\title{
Listeria grayi
}

National Cancer Institute

\section{Source}

National Cancer Institute. Listeria grayi. NCI Thesaurus. Code C86499.

A species of facultatively anaerobic, Gram positive, rod shaped bacteria in the phylum Firmicutes. This species is motile, catalase positive, oxidase and indole negative, nitrate reduction variable, produces acid from glucose and mannitol and hydrolyzes esculin. L. grayi is found in soil and animal feces and generally reg arded as nonpathogenic, although infection has been documented in immunocompromised patients. 